\title{
Urtica dioica Induces Cytotoxicity in Human Prostate Carcinoma LNCaP Cells: Involvement of Oxidative Stress, Mitochondrial Depolarization and Apoptosis
}

\author{
Arkene Levy ${ }^{1^{*}}$, Dhandayuthapani Sivanesan², Rajeswari Murugan ${ }^{3}$, Jackie \\ Jornadal $^{3}$, Yanira Quinonez ${ }^{3}$, Mark Jaffe ${ }^{3}$ and Appu Rathinavelu ${ }^{2}$ \\ ${ }^{1}$ Pharmacology Section, Department of Basic Medical Sciences, University of the West Indies, Mona Campus, Jamaica, \\ ${ }^{2}$ Rumbaugh Goodwin Institute for Cancer Research, Nova Southeastern University. 1850 NW 69th Ave, Suite 5 Plantation, FL \\ 33313, ${ }^{3}$ Nova Southeastern University, 3301 College Ave Fort Lauderdale, FL 33314, USA,
}

*For correspondence: Email: arkene_levy@yahoo.com; Tel: 1876-288-6040; Fax: 1876-977-3823,

\begin{abstract}
Purpose: To evaluate the cytotoxic mechanisms of an extract from the leaves of the Urtica dioica (UD) plant in $L N C a P$ prostate cancer cells.

Methods: $L N C a P$ cells were exposed to the UD extract for $24 \mathrm{hrs}$ and cell viability assessed using the MTT assay. Reactive oxygen species generation was assessed using the NBT assay and mitochondrial membrane potential using $\mathrm{JCl}$-aggregation. DNA fragmentation patterns and cleavage of poly (ADPribose) polymerase were assessed using western blot and caspase activation via colorimetric assay. Results: The viability of $L N C a P$ cells was significantly decreased in a dose-dependent manner following 24-h treatment with the UD extract. The reactive oxygen species levels were also significantly increased and mitochondrial depolarization was evident. DNA fragmentation, PARP cleavage and an increase in the activities of caspases 3 and 9 were observed in cells treated with the UD extract and this confirmed the induction of apoptosis as the major cytotoxic modality for this extract.

Conclusion: The results confirm that the cytotoxic activity of UD aqueous extract in LNCaP cells is mediated through oxidative stress and apoptosis. These findings could hold positive implications for the potential use of UD extract in prostate cancer therapy.
\end{abstract}

Keywords: Urtica dioica, Cytotoxicity, DNA fragmentation, PARP cleavage, Caspases, Prostate cancer

Tropical Journal of Pharmaceutical Research is indexed by Science Citation Index (SciSearch), Scopus, International Pharmaceutical Abstract, Chemical Abstracts, Embase, Index Copernicus, EBSCO, African Index Medicus, JournalSeek, Journal Citation Reports/Science Edition, Directory of Open Access Journals (DOAJ), African Journal Online, Bioline International, Open-J-Gate and Pharmacy Abstracts

\section{INTRODUCTION}

Although substantial advances have been made in therapeutic options, cancer of the prostate remains a great public health concern globally. It is highly prevalent in Jamaica and the wider Caribbean population where it is the leading site of cancer related deaths in men [1,2] In the United States prostate cancer is the second leading cause of cancer death in men and globally it is second most frequently diagnosed cancer [1]. Chemotherapeutic intervention in prostate cancer is particularly common in cases of relapse following primary androgen suppression treatment or metastasis beyond the prostate. Taxanes such as docetaxel and cabazitaxel in combination with prednisone is the standard first-line chemotherapeutic regimen for prostate cancer [3]. Taxane-based therapy, however, is often accompanied by high levels of resistance and adverse events including bleeding, anemia, neuropathy and depressed cardiac function [4], thus indicating a need for more efficacious therapies in prostate cancer. 
Urtica dioica (UD) commonly called stinging nettle is a shrub in the family Urticaceae. The plant is widely distributed throughout Europe, Asia and North America [5] and has diverse therapeutic properties. It has been reported to exhibit anti-arthritic and analgesic properties [6, 7] as well as antioxidant, antimicrobial and antiulcer activity [8]. Extracts of UD have also shown clinical efficacy in alleviating symptoms of benign prostatic hyperplasia $[9,10]$. Antiproliferative effects of UD were previously reported in prostatic carcinoma cells [11] but there is lack of data regarding the cytototoxic effect of UD in prostate cancer. Therefore, the present study was designed to examine the cytotoxic effects of aqueous extract of UD leaves on human prostatic carcinoma LNCaP cells and the associated mechanisms. We evaluated several events involved in induced cell death including increased oxidative stress, mitochondrial depolarization, DNA fragmentation, poly (ADP-ribose) polymerase (PARP) cleavage and caspase activation. Data from the present study demonstrate that UD aqueous extract produces a potent cytotoxic effect in LNCap cells that is mediated through apoptosis.

\section{EXPERIMENTAL}

\section{Preparation of aqueous UD extract}

Urtica dioica leaves were obtained from Blessed Herbs (Sunrise Florida, USA). The dried leaves were milled to a powder and 15 grams of the UD powder was boiled with $250 \mathrm{ml}$ of HPLC grade distilled water for 20 min with occasional stirring. The decoction was filtered using a cheese cloth flowed by filter paper (Whatman \#1). The filtered solution was then evaporated to dryness at using a rotor evaporator yielding a dark green residue .The solid extract (yield: $16 \% \mathrm{w} / \mathrm{w}$ ) obtained was stored at $4{ }^{\circ} \mathrm{C}$ for further use.

\section{Cell culture}

LNCaP cells (ATCC, Washington, DC, USA) were maintained at $37{ }^{\circ} \mathrm{C}$ in a humidified atmosphere of $5 \% \mathrm{CO}_{2}$ and propagated as adherent monolayers in $90 \%$ RPMI medium containing $10 \%$ fetal bovine serum (FBS) and 1 $\%$ penicillin/streptomycin. Cells were subcultured at approximately $80 \%$ confluence and harvested for the various studies after brief trypsinization.

\section{MTT cytotoxicity assay}

LNCaP cells were harvested and counted, then seeded in 96-well microplates $\left(1 \times 10^{5}\right.$ cells/well $)$ and incubated $\left(37{ }^{\circ} \mathrm{C} / 5 \% \mathrm{CO}_{2}\right)$ for $24 \mathrm{~h}$ prior to the addition of the UD aqueous extract (UD-AQ).
For treatment of cells, the UD-AQ extract was diluted using sterile distilled water to final concentrations of $20,40,60$ and $80 \mu \mathrm{g} / \mathrm{ml}$ which were added in triplicate to cells. Control cells were treated with vehicle only as negative control. The treated cells were incubated for 24 hrs $\left(37^{\circ} \mathrm{C} / 5 \% \mathrm{CO}_{2}\right)$. Following incubation, $10 \mu \mathrm{l}$ of the MTT (3-[4, 5-dimethylthiazol-2-yl]-2,5diphenyltetrazolium bromide) reagent was added to each well. The cells were further incubated for $4 \mathrm{hrs}$ in the dark, after which $100 \mu \mathrm{l}$ of DMSO was added and incubated overnight under the same conditions. Absorbance (OD) was read at $490 \mathrm{~nm}$ using a Multiskan microplate reader (Molecular Devices Inc., Sunnyvale, CA, USA). The relative cell viability in percentage was calculated as (Absorbance 490 of treated samples/Absorbance 490 of untreated samples) $\times$ 100. The $I C_{50}$ for the extract was determined using linear regression from the dose-response curve.

\section{Assay for Caspase 3 and 9 activities}

In order to evaluate the involvement of caspases in UD-AQ induced cytotoxicity, the activities of caspase 3 and 9 were measured using a colorimetric assay. Following treatment of LNCaP cells with UD-AQ extract $(50 \mu \mathrm{g} / \mathrm{ml})$ in 6well plates, cells were collected by centrifugation and lysed with lysis buffer (1\% Triton X-100, $0.32 \mathrm{M}$ sucrose, $5 \mathrm{mM}$ EDTA, $10 \mathrm{mM}$ Tris- $\mathrm{HCl}$, $\mathrm{pH}$ 8.0, $2 \mathrm{mM}$ dithiothreitol, $1 \mathrm{mM}$ PMSF, $1 \mu \mathrm{g} / \mathrm{ml}$ Aprotinin, $1 \mathrm{mg} / \mathrm{ml}$ Leupeptin). Lysates were transferred to 96-well microplates and incubated with $2 \mathrm{mM}$ substrate specific for caspase- 3 and 9 in triplicate respectively at $37^{\circ} \mathrm{C}$ for $1 \mathrm{~h}$. Specific substrate was DVED-pNA for caspase-3 and LEHD-pNA for caspase-9. The production of cleaved p-nitroanilide from each substrate was measured at $405 \mathrm{~nm}$ using a Molecular Dynamics SpectraMax 250 microplate reader.

\section{DNA fragmentation assay}

DNA fragmentation patterns were examined by electrophoresis of extracted genomic DNA from the LNCaP cells following treatment with UD-AQ extract $(50 \mu \mathrm{g} / \mathrm{ml})$. Cells were grown in T-25 culture flasks and incubated with the UD-AQ extract for $24 \mathrm{~h}$. Topotecan $(10 \mu \mathrm{M})$ was used as positive control. After incubation, the cells were harvested and washed with phosphate-buffered saline (PBS). Cells were re-suspended in $200 \mu \mathrm{l}$ of PBS supplemented with $20 \mu$ l of proteinase K. The DNA was extracted using the Qiagen DNeasy Kit by following the manufacturer's protocol. The samples were subjected to electrophoresis at $80 \mathrm{~V}$ for $2 \mathrm{~h}$ in $1.5 \%$ agarose gel containing $5 \mu \mathrm{l}$ of ethidium bromide. DNA 
fragmentation patterns were visualized using UVP image analyser.

\section{JC-1 mitochondrial membrane potential $(\Delta \Psi \mathrm{m})$ analysis}

Mitochondrial membrane potential $(\Delta \psi \mathrm{m})$ was analyzed using 5,5',6,6'-tetrachloro-1,1',3,3'tetraethylbenzimidazolcarbocyanine iodide (JC1); a fluorescent compound. Mitochondria with intact membrane potentials induce JC-1 aggregation which results in the mitochondria fluorescing a red color. In depolarized mitochondria, there is no $\mathrm{JC}-1$ aggregation and this produces green fluorescence. LNCaP cells were cultured in a 24 well plate until $80 \%$ confluency was reached. Cells were treated with UD-AQ $(50 \mu \mathrm{g} / \mathrm{ml})$ then incubated for $24 \mathrm{~h}$ at 37 ${ }^{\circ} \mathrm{C}$. The JC-1 dye $(25 \mu \mathrm{L})$ was then added to each well and incubated for a further $15 \mathrm{~min}$. The cells were then analyzed with a fluorescent microscope at excitation/emission $=540 / 570 \mathrm{~nm}$ for red fluorescence (viable cells) and 485/535 $\mathrm{nm}$ for green fluorescence (apoptotic cells).

\section{Nitroblue tetrazolium (NBT) reactive oxygen species assay}

The NBT assay is quantitative method for determining oxidative bursts based on the conversion of soluble nitroblue tetrazolium (NBT) to the insoluble NBT-diformazan by reactive oxygen species (ROS) such as the superoxide anion. LNCaP cells $\left(1 \times 10^{5}\right.$ cells/well) were propagated in a six-well plate incubated with UD$A Q$ extract as described above for $24 \mathrm{~h}$. Treated cells were then incubated at $37{ }^{\circ} \mathrm{C}$ with NBT (1 $\mathrm{mg} / \mathrm{ml}$ ) in HBSS medium for $4 \mathrm{~h}$ in the dark. Following incubation, reduced NBT was solubilized with DMSO. The absorbance was measured for each well at $560 \mathrm{~nm}$ using an ELISA plate reader. The ROS production levels were calculated by comparing the absorbance values of the treated samples to that of the control samples.

\section{Western blotting: detection of cleaved PARP}

Protein extracts were prepared for western blotting following treatment of LNCaP cells with UD-AQ $(50 \mu \mathrm{g} / \mathrm{ml})$ and topotecan $(10 \mu \mathrm{M})$ as previously described for $24 \mathrm{~h}$. Protein was extracted using the Qiagen Protein Purification kit, and quantified according to the manufacturer's protocol. In total, $30 \mu \mathrm{g}$ of sample proteins were separated by SDS-PAGE and transferred to nitrocellulose membrane. Membranes were blocked with $5 \%$ fat-free dry milk in $1 \times$ Tris-buffered saline (TBS) and incubated with the primary antibody to PARP
(Cell Signalling Technology, USA). Protein bands were detected by incubating with horseradish peroxidase-conjugated antibodies (Sigma Aldrich, USA) and visualized with enhanced chemiluminescence reagent

\section{Statistical analysis}

All experiments were performed in triplicate, and data is presented as means \pm SEM. Student's ttest (with SigmaPlot 10.0) was used for analysis of the difference between UD-AQ treated and control groups and statistical significance of $p<$ 0.05 considered significant.

\section{RESULTS}

\section{Effect of UD-AQ extract on cell viability}

The viability of LNCaP cells was significantly ( $p \leq$ 0.05 ) reduced in a dose dependent manner by the UD-AQ extract (Figures 1) when compared to the control cells that were exposed to aqueous vehicle only. The $\mathrm{IC}_{50}$ value of the extract was $42 \mu \mathrm{g} / \mathrm{ml}$ and this confirmed potent cytotoxic activity.

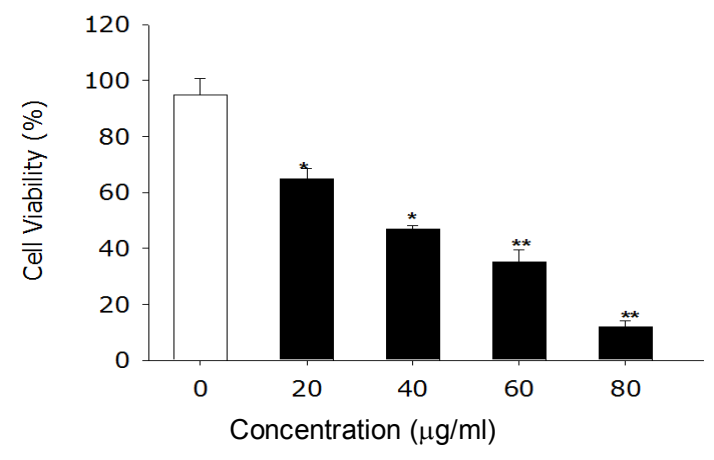

Figure 1: Effect of UD-AQ extract on $\angle N C a P$ cell viability. Cells were incubated with UD-AQ extract (a) at concentrations of $20,40,60$ and $80 \mu \mathrm{g} / \mathrm{ml}$ for $24 \mathrm{~h}$. Data is presented as the mean \pm SEM from triplicate experiments. Asterisks represent values significantly different from the control cells exposed to sterile water () only, $\left.{ }^{*}(p \leq 0.05),{ }^{* *} p \leq 0.005\right)$. UD-AQ extract produced a significant and dose dependent reduction in cell viability with $I_{50}$ value of $42 \mu \mathrm{g} / \mathrm{ml}$.

\section{UD-AQ induces PARP cleavage in LNCaP cells}

We utilized PARP cleavage as an indicator of apoptosis in the present study. UD-AQ extract and the standard anti-cancer agent topotecan induced PARP cleavage in LNCaP cells (Figure 2). PARP cleavage was not observed in distilled water treated controls and this confirmed apoptosis as a modality of UD-AQ induced cytotoxicity (Figure 2). 


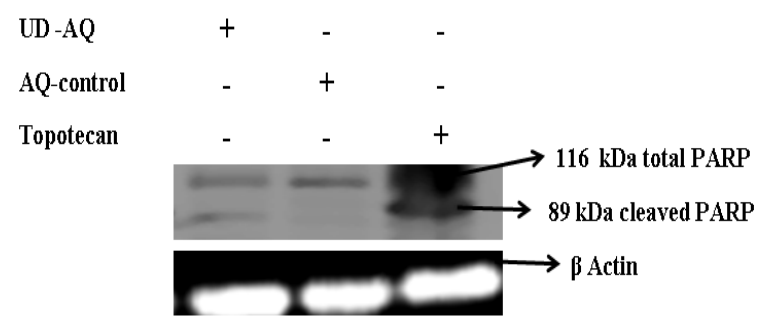

Figure 2: Proteolytic cleavage of PARP in $L N C a P$ cells exposed to UD-AQ extract. Cell lysates were analyzed by Western blotting for PARP after exposure to UD-AQ extract $(50 \mu \mathrm{g} / \mathrm{ml})$ and topotecan $(10 \mu \mathrm{M})$ for $24 \mathrm{hrs}$. $\beta$ Actin (43kDa) was also detected as the loading control. Cleaved PARP fragments $(89 \mathrm{kDa})$ are evident in UD-AQ and topotecan treated cells.

\section{DNA fragmentation in UD-AQ treated LNCaP cells}

To further evaluate the involvement of apoptosis in the cytotoxic effects of the UD-AQ extract; we evaluated DNA fragmentation patterns in response to $24 \mathrm{hr}$ exposure to the extract as internucleosomal cleavage of cellular DNA by endonucleases is indicative of apoptotic cell death. The extract and topotecan induced distinct DNA fragmentation patterns in contrast to vehicle treated cells which showed no fragmented DNA (Figure 3).

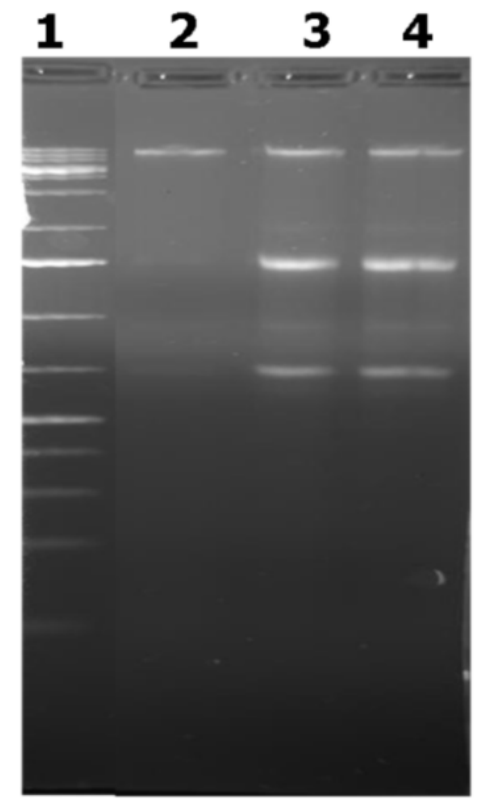

Figure 3: UD-AQ extract induces $D N A$ fragmentation in LNCaP cells. Agarose gel (1.5\%) electrophoresis depicting DNA fragmentation patterns in $L N C a P$ cells treated with UD-AQ extract, distilled water and topotecan for 24 hrs. Lane 1, 100 bp DNA ladder; lane 2 , control cells exposed to aqueous vehicle/distilled water; lane 3, cells treated with UD-AQ $(50 \mu \mathrm{g} / \mathrm{ml})$; lane 4 , cells treated with topotecan $(10 \mu \mathrm{M})$ as positive control. DNA fragmentation patterns were visualized using a UVP image analyzer.

\section{Caspase activation by UD-AQ extract}

The activities of caspase- 3 and caspase- 9 were significantly $(p \leq 0.001)$ increased by $5( \pm 0.4)$ and $2.5( \pm 0.7)$-fold respectively in UD-AQ treated cells when compared to the vehicle treated control cells. This indicated the activation of the apoptotic pathway. In comparison, when compared to the aqueous control, the standard chemotherapeutic agent topotecan produced a $10( \pm 0.1, p \leq 0.0004)$ and $5.5( \pm 0.4, p \leq 0.001)$ fold increase in caspase 3 and caspase 9 activities, respectively

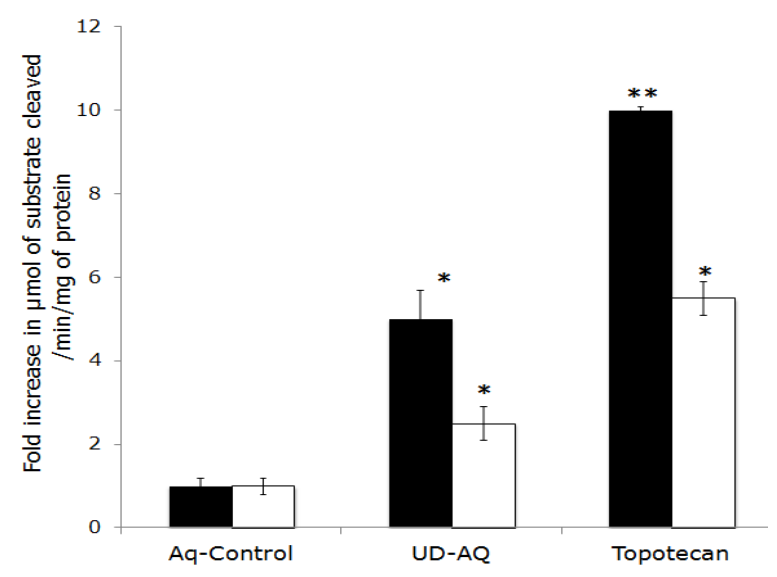

Figure 4: UD-AQ extract activates Caspases 3 and 9 in LNCaP cells. Caspase 3 (ロ) and 9 (口) activity via enzymatic cleavage of Ac-LEHD-pNA and Ac$D E V D p N A$ in lysates from $L N C a P$ cells following 24-h exposure to UD-AQ $(50 \mu \mathrm{g} / \mathrm{ml})$. Data is presented as the mean \pm S.E.M. from triplicate experiments. Asterisks represent values significantly different from the vehicle control $\left({ }^{*} p \leq 0.001,{ }^{* *} p \leq 0.0004\right)$. When compared with the control, UD-AQ increased the activities of caspases 3 and 9 by $5( \pm 0.4)$ and $2.5( \pm$ 0.7)-fold, respectively.

\section{Effect of UD-AQ extract on mitochondrial membrane potential $(\Delta \Psi \mathrm{m})$}

Treatment of LNCaP cells with UD-AQ resulted in decreased $\Delta \psi \mathrm{m}$, depicted by the shift from red to green in figure (5a). There was no significant change in $\Delta \psi \mathrm{m}$ in control cells (Figure $5 \mathrm{~b}$ ). The loss of mitochondrial potential therefore confirms mitochondrial depolarization as a mechanism involved in the cytotoxicity induced by UD-AQ.

\section{Effect of UD-AQ extract on ROS generation in LNCaP Cells}

The UD-AQ extract induced significant $(p \leq 0.01)$ ROS generation in LNCaP cells that was $2.5 \pm$ 0.2 -fold greater than in the control cells (Figure 6). This confirms that ROS generation is involved in UD-AQ mediated cytotoxicity. 

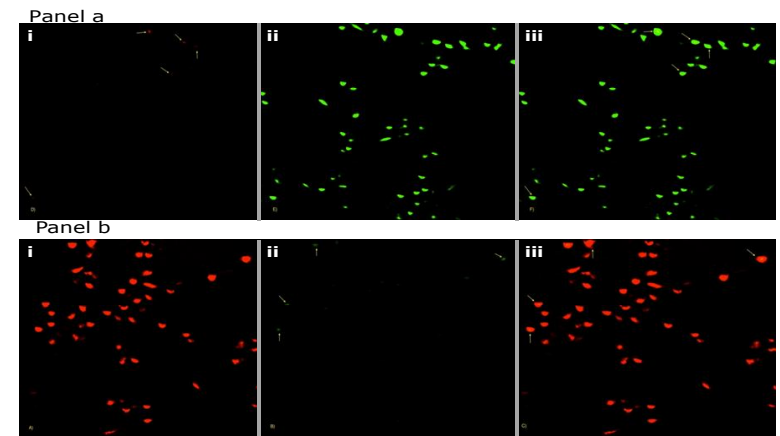

Figure 5: Effect of $U D-A Q$ on $\triangle \psi m$ in $L N C a P$ cells. Representative micrographs of JC-1 mitochondrial membrane potential staining in $L N C a P$ cells after exposure to UD-AQ (50 $\mathrm{\mu g} / \mathrm{ml})$ for $24 \mathrm{~h}$. Images were captured by Lieca fluorescence microscope system at Mag $x$ 20. Panel a, depicts cells treated with UD-AQ. Panel $b$ shows cells treated with distilled water (control). (i) JC-1 aggregates showing red fluorescence; (ii) JC-1 monomers showing green fluorescence; and (iii) overlay of red and green fluorescence. Red fluorescence indicates mitochondria with intact $\Delta \psi \mathrm{m}$. Green fluorescence indicates depolarized mitochondria which was evident in UD-AQ treated cells.

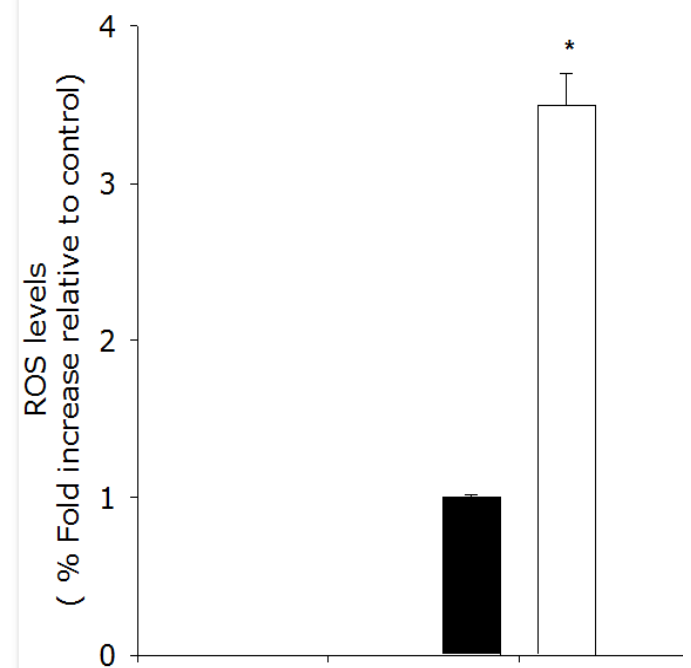

Figure 6: ROS generation in $\angle N C a P$ cells treated with UD-AQ extract. ROS levels ( $\mu$ m of NBT reduced/ $1 \times 10^{5}$ cells/ $\mathrm{ml}$ ) determined from percent absorbance of formazan relative to aqueous control (घ) following 24-h exposure of $L N C a P$ cells to $U D-A Q$ extract ( $\square$ ). Data is presented as the mean \pm S.E.M. from triplicate experiments. Asterisk represents value significantly different from the control $\left({ }^{*} p \leq 0.01\right)$. When compared with the contro,I UD-AQ produced a 2.5 ( \pm 0.2)-fold increase in ROS levels.

\section{DISCUSSION}

The use of herbal based complementary medicine among prostate cancer patients is increasing significantly as such therapies are believed to represent a more affordable and potentially effective alternative for controlling the outcome of this disease when compared to conventional therapies $[12,13]$. The increased usage of herbal products in prostate cancer is also fueled by the limitations of current conventional therapies which include severe side effects and high incidence of resistance [4]. Multiple compounds with diverse chemotherapeutic properties have been derived from herbs with strong evidence of efficacy in prostate cancer [14] and the present study continues the scientific exploration of herbal products for such chemotherapeutic activity.

An aqueous extract from the leaves of the Stinging nettle (UD-AQ) plant, was evaluated for anti-cancer activity and related mechanisms in the LNCaP prostatic carcinoma cell line. We first examined the cytotoxic effect of the UD-AQ extract at concentrations ranging from $(0-80$ $\mu \mathrm{g} / \mathrm{ml}$ ) using the MTT assay. We found that there was a significant reduction in LNCaP cell viability in a dose dependent manner following 24-h exposure with an $\mathrm{IC}_{50}$ value of $42 \mu \mathrm{g} / \mathrm{ml}$. This concentration is similar to previous data from preliminary studies showing that an aqueous extract from the aerial parts of the UD plant induced cytotoxicity in MCF-7 and MDA 231 breast cancer cell lines with $\mathrm{IC}_{50}$ value of 34 $\mu \mathrm{g} / \mathrm{ml}[15]$.

To investigate the mechanisms involved in UD$A Q$ induced cell death we evaluated the involvement by apoptosis firstly through DNA fragmentation and poly ADP ribose polymerase (PARP) cleavage analysis following $24 \mathrm{hr}$ exposure of LNCaP cells to the UD-AQ extract. Apoptosis is characterized biochemically by the production of 180-200 bp internucleosomal DNA fragments resulting from the activation of endonucleases [16]. This produces a characteristic pattern of DNA cleavage into a 180 base pair "DNA ladder" that can be visualized by agarose gel electrophoresis with an ethidium bromide stain and ultraviolet illumination [16]. The UD-AQ extract produced characteristic apoptotic fragmentation patterns in our LNCAP cells. PARP is a nuclear enzyme that is integral in the DNA repair process and its cleavage by caspase-3 during apoptosis disables DNA repair [17]. PARP cleavage was evident in UD-AQ treated cells and along with DNA fragmentation observed, this confirmed apoptosis as a modality of UD-AQ induced cytotoxicity.

We subsequently evaluated the involvement of the caspase cascade in the UD-AQ induced cell death, as apoptotic death of mammalian cells is typically mediated by these cysteine proteases of which caspases 3, 8 and 9 are key players [18]. We found that treatment of LNCaP cells with the UD-AQ extract increased the activities of 
caspase 3 and 9 following 24 hour treatment. The apoptotic pathway can be activated by intrinsic or extrinsic events. In the extrinsic pathway,the ligation of a transmembrane death receptor leads to activation of caspase-8, while in the intrinsic apoptotic pathway the release of cytochrome $\mathrm{c}$ due to loss of $\Delta \psi \mathrm{m}$, leads to caspase 9 activation [19]. The activation of caspase 3 is common to both intrinsic and extrinsic apoptotic pathways, and this is a characteristic confirmatory pattern of apoptosis [19]. Therefore, our results confirm that UD-AQ activates the intrinsic apoptotic pathway.

In addition to the activation of caspases 3 and 9, the UD-AQ extract also induced mitochondrial depolarization in LNCaP cells as evidenced by fluorescent shift from red to green following JC-1 staining. Taken together these findings outline a pathway of UD-AQ induced cytotoxicity that involves the activation of the intrinsic apoptotic pathway subsequent to mitochondrial depolarization.

Mitochondrial depolarization is generally due to aberrant mitochondrial function which is presumed to be secondary to opening of the mitochondrial permeability transition pore (MPTP), allowing passage of ions and small molecules [20]. This depolarization often serves as the nodal point where diverse apoptotic stimuli translate from initiation into execution [21] through cytochrome $c$ release which leads to the activation of caspase-9 with subsequent activation of the central executioner of apoptosis caspase-3 [18]. Activation of caspase-3 eventually triggers the caspase-activated DNase, which enters the nucleus and thus causes PARP cleavage and DNA fragmentation [18].

We conjectured that UD-AQ induced mitochondrial depolarization might be associated with ROS release as production of endogenous ROS as mitochondrial by products of respiration is tightly controlled by MMP and disruption in the ROS homeostasis plays a critical role in the regulation of mitochondrial dysfunction and apoptotic events [22]. Oxidative stress in mitochondria may cause further damage to both mitochondrial DNA and the electron transport chain, thus amplifying the "respiratory" malfunctions [23]. Furthermore, excessively generated ROS has been linked to reduction of mitochondrial membrane potential in apoptotic cancer cells including LNCaP cells [20, 24]. We assayed ROS generation in UD-AQ treated LNCaP cells after 24-h treatment and results depict a 2.5-fold increase in ROS levels in these cells when compared to controls, supporting the hypothesis that UD-AQ induced apoptosis involved increased ROS generation.

The chemical constituents of aqueous nettle leaf extracts are diverse and over 100 compounds have been described including polyphenols (eugenol, flavones), phytosterols (cholecalciferol, carnosol) and flavonoids such as quercitin and Kaempherol $[15,25,26)$. Carnosol has demonstrated anti-proliferative activity against LNCaP cells [27] and more interestingly the compounds quercitin and kaempferol have been shown to induce apoptotic death of LNCaP cells via PARP cleavage and DNA fragmentation [28] and could be responsible for the cytotoxic activities seen in the current study. However we will not speculate on the bioactive principles in our extract at this time but will confirm the active chemical constituent (s) in future chromatographic studies.

\section{CONCLUSION}

The mechanistic implication of our data is that UD-AQ mediated ROS production, linked to mitochondrial dysfunction is the pivotal event that triggered the apoptotic death of LNCaP cells which was subsequently evidenced by DNA fragmentation and PARP cleavage effected through the activation of caspases 3 and 9 . The current results support the hypothesis that UD$A Q$ may be a very useful anticancer drug source targeted specifically at prostate cancer. Future extensions of the present study will be aimed at further validating this hypothesis.

\section{ACKNOWLEDGEMENT}

The Authors would like to acknowledge the Rumbaugh Goodwin Research Institute and the Health Professions Department at Nova Southeastern University for funding the present research.

\section{REFERENCES}

1. Jemal A, Bray F, Center MM, Ferlay J, Ward E, Forman D. Global Cancer Statistics. Cancer J Clin 2011; 61(2): 69-90.

2. Gibson TN, Hanchard B, Waugh N. Age-specific incidence of cancer in Kingston and St Andrew, Jamaica, 2003-2007. West Indian Med J 2010; 59: 456-464.

3. Petrányi Á. The treatment of castration-resistant prostate cancer. Magy Onkol 2012; 56(4): 219-228.

4. Hwang $C$. Overcoming docetaxel resistance in prostate cancer: A perspective review. Therapeutic Advances in Medical Oncology 2012; 4: 329-340.

5. Bisht S, Bhandari S, Bisht NS. Urtica dioica (L): an undervalued, economically important plant. Agricultural Science Research Journals 2012; 2(5): 250-252.

6. Alford $L$. The use of nettle stings for pain. Altern Ther Health Med 2007; 13 (6): 58. 
7. Randall C, Meethan K, Randall H, Dobbs F. Nettle sting of Urtica dioica for joint pain: an exploratory study of this complementary therapy. Compl Therap Med 1999; 7(3): 126-131.

8. Gülçin I, Küfrevioglu OI, Oktay M, Büyükokuroglu ME. Antioxidant, antimicrobial, antiulcer and analgesic activities of nettle (Urtica dioica L.). J Ethno Pharmacol 2004; 90(2-3): 205-215.

9. Safarinejad MR. Urtica dioica for treatment of benign prostatic hyperplasia: a prospective, randomized, double-blind, placebo-controlled, crossover study. J Herb Pharmacother 2005; 5(4):1-11.

10. Krzeski T, Kazón M, Borkowski A, Witeska A, Kuczera J. Combined extracts of Urtica dioica and Pygeum africanum in the treatment of benign prostatic hyperplasia: double-blind comparison of two doses. Clin Ther 1993; 15(6):1011-1020.

11.Konrad L, Müller HH, Lenz C, Laubinger H, Aumüller G, Lichius JJ. Antiproliferative effect on human prostate cancer cells by a stinging nettle root (Urtica dioica) extract. Planta Med 2000; 66(1):4447.

12. Klempner SJ, Bubley G. Complementary and alternative medicines in prostate cancer: from bench to bedside. Oncologist 2012; 17(6): 830-837.

13. McDermott CL, Blough DK, Fedorenko CR, Arora NK, Zeliadt SB, Fairweather ME, Oakley-Girvan I, Van Den Eeden SK, Ramsey SD. Complementary and alternative medicine use among newly diagnosed prostate cancer patients. Support Care Cancer 2012; 20(1): 65-73.

14. Mukherjee AK, Basu S, Sarkar N, Ghosh AC. Advances in Cancer Therapy with Plant Based Natural Products. Current Medicinal Chemistry 2001; 8 . 1467-1486.

15. Guler ER. Investigation of Chemopreventif Properties of Urtica Dioica L. in MCF-7 and MDA 231 Breast Cancer Cell Lines. New Journal of Medicine 2013; 30(1): 50-53

16. Oberhammer F, Wilson JW, Dive C, Morris ID, Hickman JA, Wakeling AE, Walker PR, Sikorska $M$. Apoptotic death in epithelial cells: cleavage of DNA to 300 and/or $50 \mathrm{~kb}$ fragments prior to or in the absence of internucleosomal fragmentation. The EMBO Journal 1993; 12 (9): 3679-3684.

17. D'Amours D, Sallmann FR, Dixit VM, Poirier GG. Gain-offunction of poly(ADP-ribose) polymerase-1 upon cleavage by apoptotic proteases: implications for apoptosis. J Cell Sci 2001; 114: 3771-3778.

18. Philchenkov A, Zavelevich $M$, Kroczak TJ, Los, $M$. Caspases and cancer: mechanisms of inactivation and new treatment modalities. Exp Oncol 2004; 26: 82-97.

19. Kim R. Recent advances in understanding the cell death pathways activated by anticancer therapy. Cancer 2005; 103: 1551-1560.

20. Kroemer G, Galluzzi L, Brenner C. Mitochondrial Membrane Permeabilization in Cell Death. Physiol Rev 2007; 87: 99-163.

21. Ling $Y H$, Liebes $L$, Zou $Y$, Perez-Soler $R$. Reactive oxygen species generation and mitochondrial dysfunction in the apoptotic response to Bortezomib, a novel proteasome inhibitor, in human H460 non-small cell lung cancer cells. J Biol Chem 2003; 278(36): 33714-33723.

22. Simon HU, Haj-Yehia A, Levi-Schaffer F. Role of reactive oxygen species (ROS)

in apoptosis induction. Apoptosis 2000; 5: 415-418.

23. Manda G, Nechifor M, Neagu TM. Reactive Oxygen Species, Cancer and Anti-Cancer Therapies. Curr Chem Biol 2009; 3: 342-366.

24. Kim Y, Xiao D, Xiao H, Powolny A, Lew K, Reilly M, Zeng $Y$, Wang Z, Singh S. Mitochondria-mediated apoptosis by diallyl trisulfide in human prostate cancer cells is associated with generation of reactive oxygen species and regulated by Bax/Bak. Mol Cancer Ther 2007; 6(5): 1599-1609.

25. Roschek RC, Fink MM, Randall SA. Nettle Extract (Urtica dioica) Affects Key Receptors and Enzymes Associated with Allergic Rhinitis. Phytother Res 2009; 23(7): 920-926.

26. Akbay $P$, Basaran $A$, Undeger $U$, Basaran $N$. In vitro Immunomodulatory Activity of Flavonoid Glycosides from Urtica dioica L. Phytother Res 2003; 17: 34-37.

27. Petiwala SM, Puthenveetil AG, Johnson JJ. Polyphenols from the Mediterranean herb rosemary (Rosmarinus officinalis) for prostate cancer. Front Pharmacol 2013; 4: 29.

28. Brusselmans $K$, Vrolix $R$, Verhoeven $G$, Swinnen J. Induction of Cancer Cell Apoptosis by Flavonoids Is Associated with Their Ability to Inhibit Fatty Acid Synthase Activity. J Biol Chem 2005; 280(7): 56365645 . 